\title{
O QUE APRENDI COM O SILÊNCIO
}

\section{LO QUE APRENDÍ DEL SILENCIO}

WHAT I LEARNED FROM SILENCE

Sandra POTTMEIER ${ }^{1}$

Caique Fernando FISTAROL ${ }^{2}$

Marta Helena Cúrio de CAETANO ${ }^{3}$

O que aprendi com o silêncio é uma autobiografia escrita por Cláudia Dias Baptista de Souza, conhecida como Coen Rōshi ou Monja Coen. Monja zen budista brasileira e missionária oficial da tradição Soto Shu, fundadora da Comunidade Zen Budista Zendo no Brasil, Monja Coen.

A obra disposta em 216 páginas, publicada em 2019, pela Editora Planeta, é constituída pelos seguintes capítulos (momentos da trajetória da Monja Coen antes e depois de seu ingresso no Budismo Zen), destacados por ela: 1. O que aprendi com o silêncio, 2. Aprendizados, 3. Novas comunidades, 4. Memórias inacabadas e, por fim, 5. Da adolescência à vida monástica.

Nela, Monja Coen (2019) narra de maneira simples, clara e envolvente "sobre suas experiências de outros tempos com o holofote da mirada bem fincado no seu tempo", deixando no decorrer da narrativa, e, portanto, de sua história, as marcas vividas e aprendidas nos distintos "pretéritos perfeitos, imperfeitos e mais que perfeitos", conforme sublinha o prefaciador, Barros Filho, na abertura do livro (COEN, 2019, p. 3).

Tais conhecimentos colhidos e cativados pela autora permitem lançar um olhar para as diferentes vivências e experiências que constituíram e ainda constituem as pessoas, mundialmente falando se referindo à Pandemia da Covid-19. É nestas crises física, mental e/ou espiritual, não apenas a circunscrita ao Coronavírus, mas em manifestações mais frequentes de ansiedade, de depressão, de solidão que cabe um recolhimento não apenas do distanciamento e/ou isolamento social, mas daquilo que aprendemos com o silêncio a partir

${ }^{1}$ Universidade Federal de Santa Catarina (UFSC), Florianópolis - SC - Brasil. Doutorado em Linguística (UFSC). ORCID: https://orcid.org/0000-0001-7328-8656. E-mail: pottmeyer@gmail.com

${ }^{2}$ Secretaria Municipal de Educação (SEMED), Blumenau - SC- Brasil. Coordenador Curricular de Língua Inglesa e da Educação Bilíngue. Mestrado em Educação (FURB). ORCID: https://orcid.org/0000-0001-76507324. E-mail: cfersf@gmail.com

${ }^{3}$ Universidade Regional de Blumenau (FURB), Blumenau - SC - Brasil. Doutoranda no Programa de PósGraduação em Educação. ORCID: https://orcid.org/0000-0002-6247-2463. E-mail: mhelenacc@gmail.com 
dessa oportunidade de reflexão, de estar consigo, de pensar em si, sobre si e nas relações humanas. Como reflete e refrata Monja Coen (2019, p. 78) em relação aos seus aprendizados e aos seus ensinamentos, se pode pensar em "Um instante de zazen, um instante Buda", em que se compreende a partir desta perspectiva e/ou filosofia que "Nada é fixo. Nada é permanente" (COEN, 2019, p. 78).

Bakhtin e seu Círculo tecendo sobre o conceito de tempo e espaço "cronotopo" (BAKHTIN, 2011[1979]) e da mobilidade da língua(gem), assim como dos sujeitos, ou seja, das pessoas, caminha na mesma direção do que preconiza Coen (2019). Um instante seja ele zazen ou Buda implica em um determinado cronotopo que é situado historicamente pelas interações que empreendemos e/ou realizamos com o Outro e com nós mesmos. Neste sentido, assim como a língua(gem), o sujeito é inacabado, inconcluso, móvel, mutável, descontínuo, o que permite se aproximar daquilo que compreende Coen (2019) sobre experiências e vivências passageiras ou duradouras. Um pouco disso e um pouco daquilo. Ou nem isso ou nem aquilo. Nessa direção é que se pode ir em busca e aos poucos se constituir e constituir esse outro-eu e outro-outro pela cultura da paz como sinaliza e defende a autora.

Trata-se de uma obra indispensável para todos que desejam conhecer um pouco mais sobre a história, os aprendizados e as vivências que constituíram a Monja Coen em sua trajetória, assim, como instiga o ser humano a refletir e a se (re)conhecer a partir do autoconhecimento, a compreender o seu Eu interior e as interações que empreendemos com os outros. Cabe destacar, que a autobiografia de Coen (2019) se constitui por um processo inverso da narrativa de sua história. Ela a inicia pelo hoje, pelo agora e vai conduzindo o leitor durante todo esse percurso da escrita do seu passado, do já vivido até fazê-lo encontrar com a Cláudia Dias Baptista de Souza da infância, da juventude, aquela que "[os] cabelos ainda eram longos e cacheados", aquela que "[de]via pesar uns 50 quilos", aquela que "[que]ria ser monja" (COEN, 2019, p. 142).

O que aprendi com o silêncio, primeiro capítulo, Coen fala das suas primeiras impressões, do seu contato inicial com o Zen-Budismo no Zen Center de Los Angeles, Califórnia, Estados Unidos, onde mais adiante, em 1983, com 36 anos de idade, faz os votos monásticos. Coen (2019) conta um pouco do dia a dia na Costa Oeste dos Estados Unidos. Da sua vida de casada e de algumas brigas com o marido que nem sabia o motivo, do trabalho no Banco do Brasil, dos passeios matinais com o grande companheiro de caminhadas, o cachorro Joshua, dos encontros na rua com seu vizinho de 86 anos de idade, Walter Sheetz. Foi Sheetz que lhe apresentou o "best-seller atual [...] Alpha Brain Waves - Ondas mentais alfa" (COEN, 2019, p. 16, grifos da autora), quando à época tinha seus "30 anos, pesava 47 quilos e 
malhava três horas por dia, todos os dias da semana, em aulas de balé clássico" (COEN, 2019, p. 16).

Ao ler o livro que chegara pelo correio, dialogava com várias pessoas (dentre elas, atletas) sobre as tais ondas mentais alfa e como elas entravam nesse(s) momento(s) alfa, que Coen se deparou com a entrevista de um monge que meditava e que "havia sido confirmado pelos neurocientistas que meditadores entravam em alfa" (COEN, 2019, p. 18). Instigada, queria saber mais sobre o tema, a meditação que fazia entrar em estado alfa. "Procurei pelo Z na lista e lá estava o Zen Center de Los Angeles. Telefonei. Havia uma prática zazen para iniciantes aos domingos de manhã" (COEN, 2019, p. 19). Mesmo encontrando dificuldades para se concentrar e meditar, pois "[a] mente pulava de um pensamento a outro" (COEN, 2019, p. 20), afirma que a partir daquele dia “iniciei práticas diárias de zazen (COEN, 2019, p. 21). Aos poucos sua rotina foi mudando. Após um retiro de sete dias e sete noites que muito a comoveu, chorava sem saber qual a razão, que Coen, decidida, largou o emprego no banco, separou-se do marido e com ele deixou o cachorro Joshua, trocou as roupas e sapatos pelo "hakama - vestuário típico dos samurais" (COEN, 2019, p. 29), largou tudo, porque desejava morar na comunidade e se tornar uma aprendiz.

Alguns destes conhecimentos são descritos pela autora no segundo capítulo, Aprendizados. Nele, Coen (2019) discorre sobre o que aprendeu no percurso na vida zazen e da busca por "Encontrar o Eu verdadeiro" (COEN, 2019, p. 75) quando passa a dedicar-se integralmente ao Zen-Budismo em seu ingresso no Mosteiro de Nagoya. A autora relata a experiência como trainee (aprendiz) em ficar sete dias e sete noites praticando o ZenBudismo, "Antes das 5h da manhã até às 21h30" (COEN, 2019, p. 80). Segundo ela, “As pernas doíam, as costas também, e os joelhos queimavam. (COEN, 2019, p. 80). Todo esse processo de transformação e constituição de Cláudia Dias Baptista de Souza para Monja Coen foi ocorrendo com instantes zazen, mudança de hábitos, corte de cabelo, mudança na vestimenta.

Neste trajeto, nomes como Maezumi Roshi, seu mestre em Los Angeles (onde tudo começou), Yogo Roshi, seu mestre de ordenação, Aoyama Shundo Docho Roshi, sua "mestra de treinamento e exemplo de inspiração de vida" (COEN, 2019, p. 200), Dogen e Kojima Sensei, mestres que foram e são suas referências até hoje. Enfatiza que: "eu havia me tornado monja, principalmente, por ter conhecido os escritos de mestre Dogen”. Sobre Kojima Sensei, Coen (2019) sublinha que, esta monja, rompeu com muitas barreiras do mundo monástico quando lutou para que as monjas pudessem ter voz e vez, vestindo com roupas que não 
fossem apenas o preto, que pudessem realizar celebrações "cerimônias, casamentos, enterros (COEN, 2019, p. 61).

Novas comunidades, terceiro capítulo, Coen (2019, p. 116) discorre sobre o trabalho que realizava em Sapporo no Templo Daishoji: a oficialização de enterros e cerimônias memoriais, que com a permissão do abade Sato Roshi, pode primeiro realizar os velórios e, mais adiante, os enterros; as saídas "todas as manhãs para orar nas casas das famílias" juntamente com seu marido, o monge Shozan, assim como o "zazen para crianças, aulas de cerimônia do chá" foram praticados por eles "[d]urante três quase três anos" naquela localidade (COEN, 2019, p. 117).

As experiências vivenciadas por Coen (2019) neste período coadunam com sua primeira palestra quando falou sobre transitoriedade e o mestre Sato Roshi the havia dito que não era suficiente falar de "nada fixo, nada permanente", instigou-a a refletir que "tudo está inter-relacionado" (COEN, 2019, p. 117). Ou seja, as minhas, as tuas, as nossas palavras e ações imprimem causa e efeito - ação e reação entre aqueles/as com quem convivemos, com quem dialogamos, com quem aprendemos e ensinamos. A partir das mobilizações do mestre Sato Roschi, Coen (2019, p. 117) nos permite um instante zazen consigo ao sublinhar que "Nada fixo, nada permanente e ao mesmo tempo tudo que fazemos, falamos e pensamos mexe na teia da vida, é um dos vetores para transformações presentes, futuras e passadas". De acordo com Coen (2019, p. 117) "até mesmo o passado é modificado com nossas palavras, pensamentos e ações no agora".

O quarto capítulo, Memórias inacabadas, a autora inicia um resgate sobre seu passado: quem foi a Monja Coen antes de ser a Monja? Como ela mesma se questiona para o leitor: "Quem era eu antes de ser monja? Com me comportava? Como vivia? Qual a transformação que ocorreu?" (COEN, 2019, p. 129). À época em que escreveu esta obra, 2019, a autora havia completado 72 anos. O que ela fez até os 28 anos, quando deu os primeiros passos para uma mudança, a nosso modo de compreender, radical, ousada e corajosa?

Mudou-se para Londres, alugou um "basement - apartamento que fica no nível abaixo da calçada" (COEN, 2019, p. 130, grifo da autora), por ter o preço mais em conta (ser mais barato). Estudou inglês no West London College. Quando Cláudia (Monja Coen) atuava como jornalista no Jornal da Tarde sempre era chamada para as "entrevistas coletivas com líderes de outros países" (COEN, 2019, p. 131) e aprender uma outra língua, neste o caso, o inglês "foi a desculpa que encontrei" (COEN, 2019, p. 131) para que ela tivesse oportunidade de viajar para Londres para aprender o idioma. 
Mudou-se para Los Angeles. Foi nesse período que casada com um norte-americano passou a procurar por Self-Realization Fellowship e a se interessar por meditação. Contudo, abandonou tal prática para se dedicar ao balé e anos mais tarde dedicou-se à meditação praticando-a no Zen Center de Los Angeles. Cláudia (Monja Coen) é filha, é irmã, é mãe, é avó, é um ser humano que buscou seu objetivo e o encontrou no Zen Budismo. Atravessou vários obstáculos até tornar-se Monja Coen. Sofreu abusos quando criança e, não tinha noção do que se tratava aquilo pela pouca idade que tinha. Tomou consciência quando já se tornara mais madura. Fez voto de castidade, conforme relata "Meu voto de castidade foi rompido, quando eu abusada por um outro monge" (COEN, 2019, p. 144). Casou-se com este monge a fim de se proteger de outros monges, como ela afirma "O jovem marido era um escudo perfeito" (COEN, 2019, p. 144).

Antes de seu ingresso na vida monástica, Monja Coen, havia se casado ainda na adolescência e teve sua única filha aos 17 anos. Largou tudo, casa, marido, filha, cachorro para se dedicar inteiramente ao Caminho Zen aos 28 anos de idade. Nesse percurso, Coen (2019, p. 180) reflete que: "Quarenta e quatro anos de prática meditativa. Já não sou quem fui. Nem sou quem serei. Se feri e incomodei, não foi com essa intenção. Procurava o Caminho, a luz, a vida. Pensava em sexo, nas drogas, na música encontraria um sentido a uma vida vazia".

Por fim, Da adolescência à vida monástica, Coen (2019) fala de sua vida antes, durante e de seu ingresso na vida monástica. Neste último capítulo tecido pela autora vislumbramos um encontro entre a Monja Coen e uma Cláudia Dias Baptista de Souza que ficou no passado. Coen (2019) discorre o início do capítulo recordando do transatlântico que vinha da Europa com seu vestido de noiva em um baú cor-de-rosa e branco. A peça havia sido bordada em seu corpo, em Paris. Relembra ainda que quando se casou aprendeu "a fritar ovos e a fazer macarrão na manteiga" (COEN, 2019, p. 190) e que desejava muito engravidar e não conseguia. Era vaidosa, "Eu ia ao cabeleireiro todos os dias. Fazia muita maquiagem, tinha unhas longas e pintadas, vestia-me com roupas discretas e elegantes, usava luva três-quartos e fumava usando piteiras" (COEN, 2019, p. 191).

Engravidou e ficou muito feliz com isso. Contudo, foi nesse período que Coen (2019) ou melhor, Cláudia junto com sua mãe foram ao hospital quando estourou a bolsa, isso pois, algumas reclamações por parte de Cláudia, fizeram o marido se mudar. Inclusive, ela relata que o marido queria que fosse menino. Segundo afirma Coen $(2019$, p. 192) e concordarmos "A vida das mulheres não era fácil. Aos homens tudo era permitido. Às mulheres, quase nada". Quando sua filha completou dois anos, Cláudia foi estudar, logo largou a faculdade 
para se dedicar ao Jornal da Tarde, "Fui ser jornalista profissional" (COEN, 2019, p. 195). Dessa vida agitada correndo do trabalho para casa com sua moto 350 para ver e levar a filha para a escola, "Bebia, fumava, trabalhava, vivia jornal, dia e noite" (COEN, 2019, p. 195). Cláudia tornou-se anos depois, em um instante zazen, a Monja Coen (2019). Instante zazen que nos muda e nos permite mudar, ensinar e aprender coletivamente, nos constitui e constitui o Outro. Como afirma Coen (2019, p. 216) "Viver é viver". Sigamos alguns ensinamentos compartilhados por esta renomável Monja Zen Budista "Mãos em prece" (COEN, 2019, p. 2016) para meditar, pedir, agradecer seja qual sua crença, sua religião, raça, credo. Todos e todas somos um só quando estamos em prece, em um instante zazen.

\section{REFERÊNCIAS}

BAKHTIN, M. M. Estética da criação verbal. Trad. Paulo Bezerra. 6. ed. São Paulo: Martins Fontes, 2011[1979].

COEN, M. O que aprendi o silêncio. São Paulo: Planeta, 2019.

\section{Como referenciar este artigo}

POTTMEIER, S.; FISTAROL, C. F.; CAETANO, M. H C. O que aprendi com o silêncio. Doxa: Rev. Bras. Psico. E Educ., Araraquara, v. 22, n. 00, e021009, 2021. e-ISSN: 25948385. DOI: https://doi.org/10.30715/doxa.v22i00.15479

Submetido em: 10/07/2021

Revisões requeridas em: 15/08/2021

Aprovado em: 02/09/2021

Publicado em: 01/10/2021 